\title{
The development of national indicators for the surveillance of osteoporosis in Canada
}

\author{
J. LeMessurier, MPH (1); S. O’Donnell, MSc (2); P. Walsh, MSc (2); L. McRae, BSc (2); C. Bancej, PhD (2); for the \\ Osteoporosis Surveillance Expert Working Group
}

This article has been peer reviewed.

\begin{abstract}
Introduction: The Public Health Agency of Canada, in collaboration with bone health and osteoporosis experts from across Canada $(n=12)$, selected a core set of indicators for the public health surveillance of osteoporosis using a formal consensus process.

Methods: A literature review identified candidate indicators that were subsequently categorized into an osteoporosis-specific indicator framework. A survey was then administered to obtain expert opinion on the indicators' public health importance. Indicators that scored less than 3 on a Likert scale of 1 (low) to 5 (high) were excluded from further consideration. Subsequently, a majority vote on the remaining indicators' level of public health importance was sought during a face-to-face meeting.

Results: The literature yielded 111 indicators, and 88 were selected for further consideration via the survey. At the face-to-face meeting, more than half the experts considered 39 indicators to be important from the public health perspective.

Conclusion: This core set of indicators will serve to inform the development of new data sources and the integration, analysis and interpretation of existing data into surveillance products for the purpose of public health action.
\end{abstract}

Keywords: osteoporosis, bone diseases, health status indicators, population surveillance, public health, consensus

\section{Introduction}

Public health surveillance is a core component of the Public Health Agency of Canada's (PHAC) mandate. ${ }^{1}$ Regular surveillance of chronic conditions, conducted by PHAC's Centre for Chronic Disease Prevention and Control (CCDPC), is essential for providing the evidence to develop, implement, enhance and evaluate chronic disease prevention and management strategies. The CCDPC collaborates with regional, provincial/territorial, national and international governments and stakeholders to share knowledge of chronic disease in order to support policies, programs and public health interventions that aim to protect and improve the health of the Canadian population. $^{2}$

Measures that reflect the health of a population or the performance of health care processes and outcomes are known as public health surveillance indicators. ${ }^{3}$ There are a number of national initiatives that report on a limited number of indicators of chronic diseases, ${ }^{4-9}$ however, a comprehensive indicator framework designed specifically for the public health surveillance of chronic diseases in Canada has not yet been described.

In consultation with PHAC's chronic disease surveillance advisory committees, the CCDPC developed a chronic disease surveillance indicator framework in 2007. ${ }^{10}$ The framework categorizes indicators from established surveillance programs including those for arthritis, cancer, cardiovascular disease, chronic respiratory diseases, diabetes and mental illnesses into one of five dimensions: (1) individual risk and protective factors; (2) health status indicators; (3) health promotion and disease prevention indicators; (4) disease management indicators; and (5) environment-specific indicators. The main objectives of this indicator framework are to support PHAC's work on the surveillance of chronic diseases and to enhance federal, provincial/territorial and local/regional capacity to use, analyze and interpret surveillance data.

National surveillance of osteoporosis was initiated by CCDPC in 2008. Osteoporosis (i.e. thin or brittle bones) is a common skeletal disorder characterized by compromised bone strength that predisposes a person to fractures. According to the most recent estimates from PHAC, 1.5 million Canadians 40 years and older (10\% of this population) reported being diagnosed with osteoporosis by a physician. ${ }^{11}$ Osteoporosis is more prevalent among older individuals and also affects more women than men. ${ }^{12}$ Its prevalence is projected to rise markedly over the next few decades as the number

\section{Author references}

1. Faculty of Medicine, Memorial University of Newfoundland, St. John's, Newfoundland and Labrador, Canada

2. Public Health Agency of Canada, Health Promotion and Chronic Disease Prevention Branch, Centre for Chronic Disease Prevention and Control, Chronic Disease Surveillance and Monitoring Division, Ottawa, Ontario, Canada

Correspondence: Siobhan O'Donnell, Public Health Agency of Canada, Health Promotion and Chronic Disease Prevention Branch, Centre for Chronic Disease Prevention and Control, Chronic Disease Surveillance and Monitoring Division, 785 Carling Avenue, A.L.: 6806A, Ottawa, ON K1A 0K9; Tel.: (613) 954-6557; Fax: (613) 941-2057; Email: siobhan.odonnell@phac-aspc.gc.ca 
of older individuals increases. ${ }^{12}$ The fractures associated with osteoporosis, specifically fractures of the spine and hip, are a significant cause of disability and mortality and a burden on health care utilization; however, there are evidence-based interventions that can substantially reduce the risk of these fractures. ${ }^{13}$

The primary objective of this study was to select a core set of indicators for the public health surveillance of osteoporosis in Canada. In the absence of indicators for a specific condition or disease, indicator developers rely on consensus-based processes. ${ }^{14}$ We selected the proposed set of indicators through

(1) the development of an osteoporosisspecific indicator framework by tailoring the dimension descriptions that make up the CCDPC framework;

(2) a systematic rapid review of the literature to identify candidate indicators; and

(3) a formal consensus process, involving bone health and osteoporosis experts from across Canada, to select a core set of indicators.

The development of this core set of indicators for the surveillance of osteoporosis will inform the development of new data sources and support the integration, analysis and interpretation of existing data into surveillance products for dissemination. The regular monitoring and reporting of these indicators will help strengthen the evidence base that will ultimately inform future public health strategies and policies for preventing and managing osteoporosis in Canada.

\section{Methods}

\section{Osteoporosis-specific indicator framework development}

An osteoporosis-specific indicator framework was developed by tailoring the descriptions of the five indicator dimensions of the CCDPC Chronic Disease Indicator Framework in order to organize the candidate indicators that were extracted from the literature. Table 1 details the five dimensions of the framework specific to osteoporosis.

TABLE 1

Osteoporosis-specific indicator framework

\begin{tabular}{|ll}
\hline Dimension & Description and examples \\
\hline $\begin{array}{l}\text { Individual protective/ } \\
\text { risk factor indicators }\end{array}$ & $\begin{array}{l}\text { Describe the individual factors (e.g. parental history of fragility/fracture), } \\
\text { health behaviours (e.g. calcium and vitamin D intake), knowledge, attitudes, } \\
\text { skills (e.g. knowledge of the benefits of weight-bearing exercise on bone } \\
\text { health), and exposures (e.g. prolonged use of bone-depleting medication) } \\
\text { that affect the risk of developing osteoporosis. }\end{array}$ \\
\hline $\begin{array}{l}\text { Health status indicators } \\
\text { Health promotion/disease } \\
\text { prevention indicators }\end{array}$ & $\begin{array}{l}\text { Describe the magnitude (e.g. prevalence, incidence) and outcomes } \\
\text { (e.g. quality of life, morbidity, mortality) of osteoporosis. }\end{array}$ \\
\hline $\begin{array}{l}\text { Describe community- or population-based interventions (e.g. bone } \\
\text { density screening programs, food fortification) that affect the development } \\
\text { indicators }\end{array}$ & $\begin{array}{l}\text { Describe whether people are screened for and how people are managing } \\
\text { their osteoporosis (e.g. use of bone-sparing medication, self-management). }\end{array}$ \\
\hline $\begin{array}{l}\text { Environment-specific } \\
\text { indicators }\end{array}$ & $\begin{array}{l}\text { Describe the broader physical (e.g. access to walking paths), social } \\
\text { (e.g. food quality or availability) and economic factors (e.g. cost of living) } \\
\text { that affect the development or management of osteoporosis. }\end{array}$ \\
\hline
\end{tabular}

Source: Adapted from Stewart, P. Chronic Disease Indicator Framework, Centre for Chronic Disease Prevention and Control, Public Health Agency of Canada; 2007 (unpublished).

\section{Literature review}

Data sources and searches. We conducted a systematic rapid review (i.e. a streamlined traditional systematic review) ${ }^{15}$ of peer-reviewed and grey literature to identify candidate indicators for osteoporosis surveillance. For the peer-reviewed literature, we searched MEDLINE, Embase, Global Health and CINAHL. Our search strategy was developed in MEDLINE with the assistance of an experienced librarian scientist. The original search strategy was modified as required for the other databases. For the grey literature, we developed an Internet search strategy using the Google search engine. See Appendix 1 for the search strategies used.

Eligibility criteria and article selection. We searched peer-reviewed studies published between 1990 and 2009 that were population-based, descriptive or observational in design and described indicators for the surveillance of osteoporosis in an adult population. Our search of the grey literature took place on May 14th, 2009. Eligible records included population-based, descriptive or observational studies, reports or survey modules containing potential indicators for the surveillance of osteoporosis in an adult population. Only records published in English were considered.
Records retrieved from our search of the health sciences databases were screened for eligibility using the bibliographic record, that is, title, authors, keywords and abstract. We obtained the full text of those articles considered potentially relevant. Records retrieved from the Google search were screened for eligibility using the information provided on the related website and/ or the full-text document (when available). The full-text records from both sources were retained for data extraction purposes when they met our eligibility criteria.

Data extraction. We developed a data extraction form based on the osteoporosisspecific indicator framework described in Table 1. Candidate indicators from the included records (peer-reviewed and non-peer-reviewed) were extracted and summarized using this form. We then reviewed and consolidated the list of indicators in order to eliminate any redundancy and classified the indicators into one of the five dimensions of the framework.

\section{Consensus process}

In order to select a core set of indicators from those retrieved from the literature, we used a two-step modified Delphi consensus-based process. ${ }^{16}$ This included the use of an electronic survey and a face-to-face meeting with members of PHAC's Osteoporosis Surveillance Expert 
Working Group. The Working Group was founded in 2008 by PHAC in collaboration with Osteoporosis Canada* in order to provide expert advice to the Agency on indicators, data sources and approaches to national surveillance of osteoporosis. It includes 10 clinician-researchers and 2 health scientists from across Canada with expertise in bone health and osteoporosis.

Step 1: Survey. Each member of the Working Group was emailed the survey and instructed to rank each candidate indicator according to its public health importance on a scale of 1 (low) to 5 (high). ${ }^{\dagger}$ In ranking an indicator for its public health importance, we asked the experts to consider (1) the size of the population that the indicator implicates or affects; (2) its importance in the prevention or management of osteoporosis; and/or (3) the severity of its potential outcome. After the experts had assigned each indicator a rank, they were asked to suggest population-based data sources (i.e. a registry or other data collection system that has information about all cases of a specific disease or injury in a geographically defined area that relates to a specific population) for a given indicator and comment on the quality of the data source. If an expert was unaware of a population-based data source, they were asked to comment on the feasibility of obtaining population-based data pertaining to the indicator. ${ }^{\ddagger}$ Information regarding the availability and feasibility of the indicators was not used for evaluation purposes at this stage of the selection process. Lastly, the experts were asked to suggest any additional indicators for the surveillance of osteoporosis that they believed were important for monitoring the bone health and the impact of osteoporosis on Canadians. The experts were given ten days to complete the survey. Extensions were granted on an as-needed basis to maximize our response rate.
Following the synthesis of the survey results, candidate indicators with a median public health importance of 3 or more were retained for further consideration. ${ }^{\S}$

Step 2: Face-to-face meeting. At the meeting, the experts were presented with the list of all the candidate indicators that had scored a median public health importance of 3 or more (as determined via the survey). Additional information presented for their consideration included the range in scores with respect to each indicator's public health importance (i.e. minimum and maximum) and relevant commentary about the potential data sources for a given indicator.

Following a review and open discussion of the survey results, the experts were asked to vote on the level of importance

FIGURE 1

Modified flow diagram showing systematic rapid review of literature to identify candidate indicators for osteoporosis surveillance

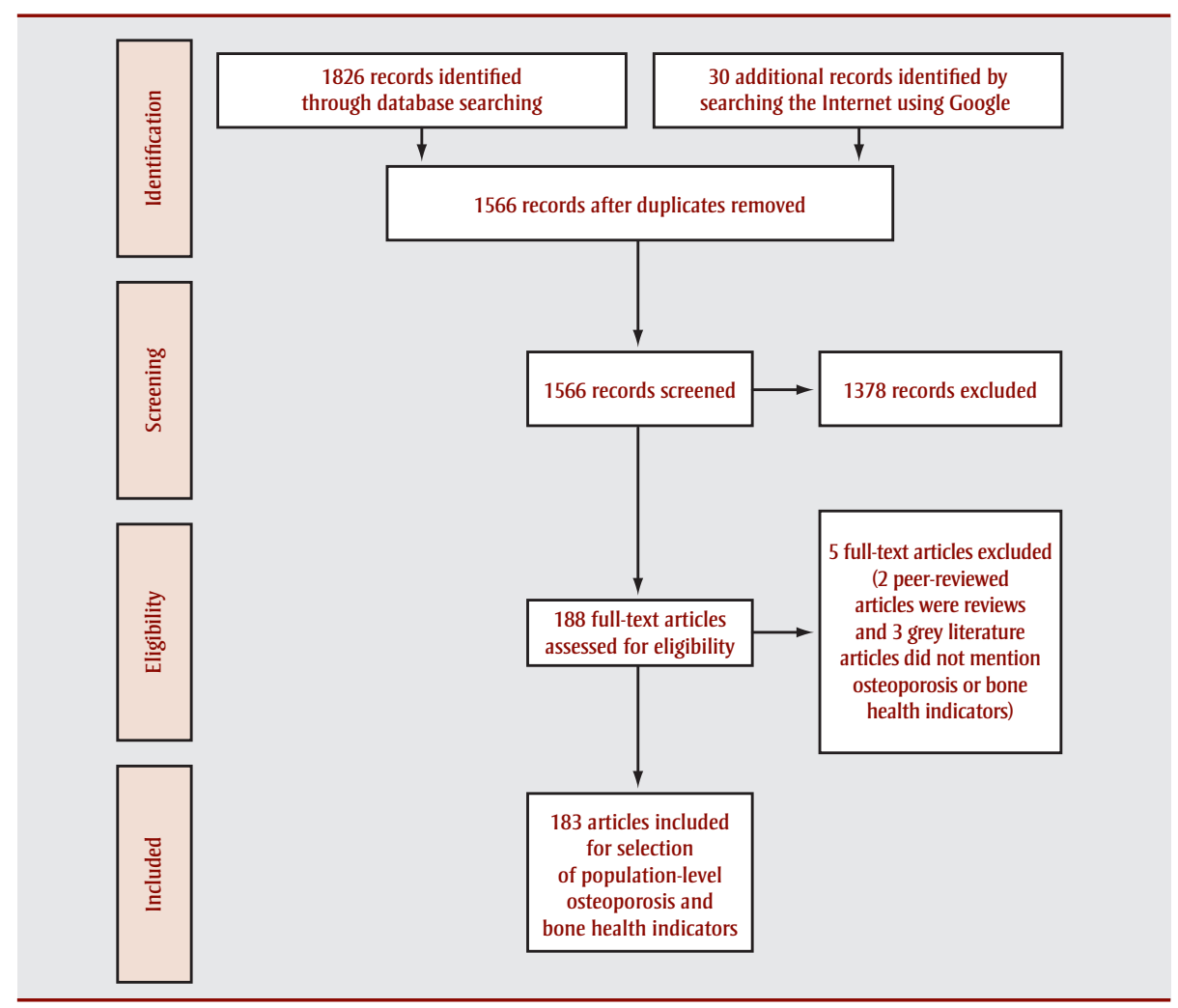

\footnotetext{
* http://www.osteoporosis.ca.

${ }^{\dagger}$ Five-point Likert scale was adapted from a project by Majumdar et al. that developed a set of indicators for the evaluation of quality improvement efforts for adults with type 2 diabetes. ${ }^{17}$

₹ Ascertaining the feasibility of obtaining a given indicator was a criterion adapted from the Project for an Ontario Women's Health Evidence-Based Report (POWER) Study's Indicator Selection Criteria. ${ }^{18}$

$\S$ Cut-off point was adapted from a study by Majumdar et al. that developed a set of quality indicators for the evaluation of quality improvement efforts for adults with type 2 diabetes. ${ }^{17}$

** The list of included records from the systematic review is available on request.
} 
FIGURE 2

Overview of study results

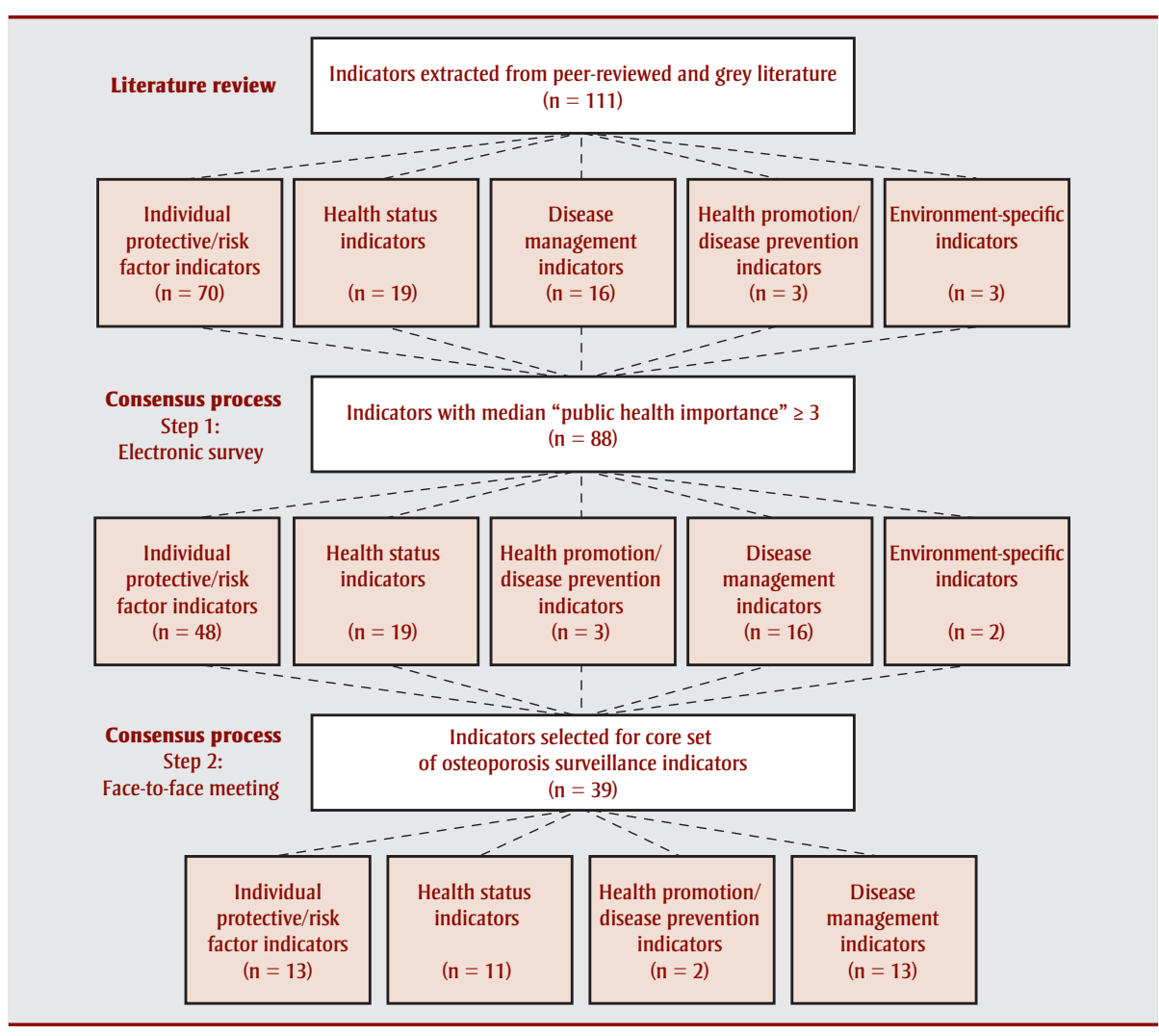

\section{Consensus Process}

Step 1: Survey. Eleven of the 12 members of the Osteoporosis Surveillance Expert Working Group completed the survey. Of the 111 candidate indicators extracted from the literature, 88 scored a median public health importance of 3 or more and were retained for further consideration (see Figure 1). The experts identified a dozen potential population-based data sources that could be used to measure these indicators (see Table 2).

Step 2: Face-to-face meeting. Nine out of the 12 members of the Working Group took part in the face-to-face consensus meeting. After an open discussion of the survey results, the majority considered 39 of the 88 candidate indicators to have a high level of importance: 13 individual protective and risk factors; 11 health status indicators; 2 health promotion and disease prevention indicators; and 13 disease management indicators (see Table 3). With respect to the remaining indicators, 28 had a medium and 19 had a low level of importance for inclusion in the core set. step towards the development of a core set of indicators for the public health surveillance of osteoporosis in Canada. The 39 indicators selected through a formal consensus process cover all aspects of osteoporosis in the population including health promotion, risk and protective factors, health status, and disease management.

We felt it was important to document this process for the following reasons: (1) to address the lack of information on public health surveillance indicator development in the published literature; (2) to serve as a reference for developing surveillance indicators for other chronic conditions/diseases; and (3) to communicate the priority areas for PHAC's future data development efforts in osteoporosis surveillance.

In a like manner, the Australian Institute for Health and Welfare and the Data Working Group of the National Arthritis and Musculoskeletal Conditions Advisory Group developed a national set of consensusbased indicators $(n=16)$ that was guided by a conceptual framework for monitoring osteoarthritis, rheumatoid arthritis and osteoporosis. ${ }^{19}$ Of this core set, 4 indicators were constructed to monitor the impact of osteoporosis: level of physical activity, osteoporosis prevalence, quality of life among those with osteoporosis and the number of hospitalizations for minimal trauma hip fractures. ${ }^{19}$

Future work will include developing operational definitions for each indicator including the rationale for its inclusion,

TABLE 2

Expert-identified population-based data sources for indicator development

\begin{tabular}{|ll}
\hline Name of data source & Abbreviation \\
\hline Canadian Multicentre Osteoporosis Study & CaMos \\
\hline Canadian Community Health Survey & CCHS \\
\hline Canadian Health Measures Survey & CHMS \\
\hline Canadian Institute for Health Information & CIHI \\
\hline Canadian Longitudinal Study on Aging & CLSA \\
\hline Manitoba Bone Density Program & MBDP \\
\hline Manitoba Centre for Health Policy & MCHP \\
\hline Maximizing Osteoporosis Management in Manitoba & MOMM \\
\hline Osteoporosis in Canada Report Card & OCRC \\
\hline Ontario Drug Benefit Program & ODB \\
\hline Recognizing Osteoporosis and Its Consequences in Quebec Programme & ROCQ \\
\hline Régie de l'assurance maladie du Québec & RAMQ \\
\hline
\end{tabular}


TABLE 3

Core set of indicators for the surveillance of osteoporosis $(n=39)$

\begin{tabular}{|c|c|c|c|}
\hline $\begin{array}{l}\text { Individual protective/ } \\
\text { risk factor indicators } \\
(\mathbf{n}=13)\end{array}$ & $\begin{array}{l}\text { Health status indicators } \\
\qquad(\mathrm{n}=11)\end{array}$ & $\begin{array}{l}\text { Health promotion/disease } \\
\text { prevention indicators } \\
\qquad(n=2)\end{array}$ & $\begin{array}{l}\text { Disease management indicators } \\
\qquad(n=13)\end{array}$ \\
\hline $\begin{array}{l}\text { - Calcium intake } \\
\text { - Dairy intake } \\
\text { - Vitamin D intake } \\
\text { - General mobility } \\
\text { - Height loss } \\
\text { - History of falls } \\
\text { - Impaired balance } \\
\text { - Knowledge of protective } \\
\text { factors for osteoporosis } \\
\text { - Knowledge of risk factors } \\
\text { for osteoporosis } \\
\text { - Maternal and/or paternal and/or } \\
\text { family history of hip fracture } \\
\text { - Number of comorbid conditions } \\
\text { - Serum } 25 \text {-hydroxycalciferol } \\
\text { - Systemic steroid therapy }\end{array}$ & $\begin{array}{l}\text { - Mortality attributable to hip fracture } \\
\text { - Mortality attributable to osteoporotic } \\
\text { fracture of any site } \\
\text { - Mortality attributable to vertebral } \\
\text { fracture/deformity } \\
\text { - Prevalence of bone mineral density } \\
\text { outcomes } \\
\text { - Prevalence of major osteoporotic } \\
\text { fracture } \\
\text { - Prevalence of minor osteoporotic } \\
\text { fracture } \\
\text { - Prevalence of vertebral deformity } \\
\text { - Prevalence/incidence/ } \\
\text { diagnosis of osteoporosis } \\
\text { - Prevalence/Incidence of } \\
\text { osteoporotic/fragility/low-energy } \\
\text { fracture } \\
\text { - Quality of life (osteoporosis specific) } \\
\text { - Self-rated health }\end{array}$ & $\begin{array}{l}\text { - Community awareness regarding } \\
\text { osteoporosis (e.g. falls prevention, } \\
\text { vitamin D intake, physical activity) } \\
\text { - Osteoporosis awareness media } \\
\text { campaign }\end{array}$ & 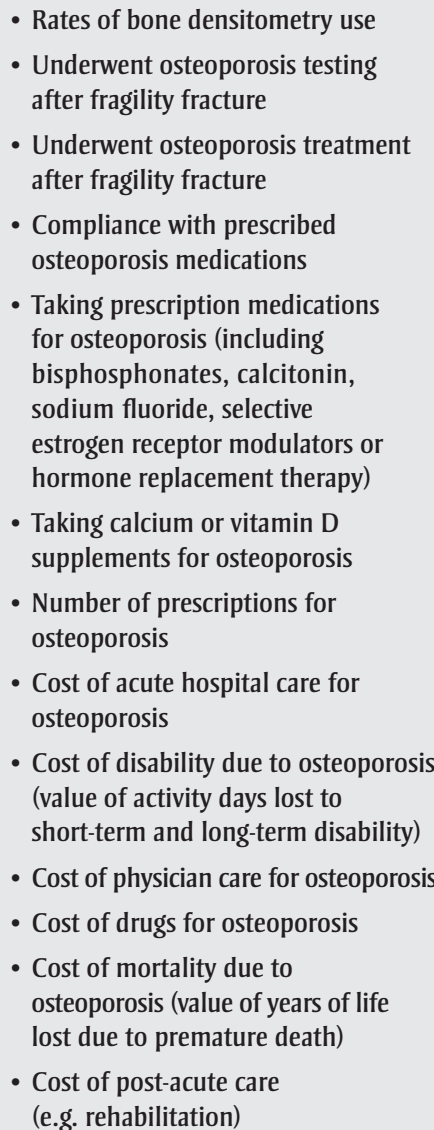 \\
\hline
\end{tabular}

the statistic or measure to be reported, the numerator and denominator to be used, existing or potential data sources and any notes, cautions or further instructions for calculating or interpreting results. ${ }^{19}$ While the Osteoporosis Surveillance Expert Working Group identified several relevant national and provincial/territorial data sources (see Table 2), additional data sources will be warranted in order to populate all 39 indicators. Those indicators on which all provinces/territories could promptly collect information could form a minimum set that should be monitored and reported on regularly; for those indicators that cannot be reported on, data development should be undertaken to permit their eventual inclusion. Eventually, an evaluation of the indicators should be carried out to determine if the individual indicators meet quality criteria and if the set of indicators is comprehensive and meets decision and policy makers' information needs. ${ }^{20}$

\section{Strengths and limitations}

Despite the systematic approach we used to establish a core set of consensus-based indicators for osteoporosis surveillance, this study has several limitations. First, accelerating the timeframes of our literature review by conducting a systematic rapid review may have resulted in our missing some relevant information and biases..$^{15} \mathrm{To}$ mitigate this possible limitation, the experts were able to suggest additional indicators that they believed important from a public health perspective in monitoring the bone health and the impact of osteoporosis on Canadians. Second, the modified Delphi consensus process relied on the opinions of a relatively small group $(n=12)$ of clinician-researchers and health scientists from across Canada. While there is no consensus regarding the method of selection, size and composition of an expert panel, the panel should reflect the full range of stakeholders who have an interest in the results of the study. ${ }^{14}$ Lastly, while the indicators selected have face validity for measuring and tracking the impact of osteoporosis on Canadians, the indicators have yet to be operationalized and therefore their feasibility, accuracy and other characteristics are unknown.

\section{Conclusion}

A formal consensus-based process was used to incorporate evidence and expert opinion for the development of a core set of national indicators for the surveillance of osteoporosis. While current data gaps will influence the composition of this core set, the regular monitoring and reporting of the indicators that can be reported on, and the development of new data sources for those indicators that cannot be reported on, are important steps towards developing a stronger evidence base that 
will ultimately inform future public health strategies and policies for preventing and managing osteoporosis in Canada.

\section{Acknowledgements}

The opinions expressed in this article are those of the authors and do not necessarily reflect the opinions of the Public Health Agency of Canada. The authors would like to thank and acknowledge the librarian scientist, Melanie Weger, for her assistance with the development of the literature search strategy as well as the Osteoporosis Surveillance Expert Working Group for their input.

Osteoporosis Surveillance Expert Working Group members: J. Brown, MD, Laval University, Quebec City, Quebec; A. Cranney, MD, MSc, University of Ottawa, Ottawa, Ontario; D.A. Hanley, MD, University of Calgary, Calgary, Alberta; S. Jaglal, PhD, University of Toronto, Toronto, Ontario; S. Jean, MSc, Institut national de santé publique du Québec, Québec City, Quebec; F. Jiwa, MHSC, DC, Osteoporosis Canada, Toronto, Ontario; S. Kaiser, MD, Dalhousie University, Halifax, Nova Scotia; D.L. Kendler, MD, University of British Columbia, Vancouver, British Columbia; W.D. Leslie, MD, MSc, University of Manitoba, Winnipeg, Manitoba; S. Morin, MD, MSc, McGill University, Montreal, Quebec; A. Papaioannou, MD, MSc, McMaster University, Hamilton, Ontario; K. Siminoski, MD, University of Alberta, Edmonton, Alberta.

Disclosure of financial and material support: None.

\section{Appendix}

\section{APPENDIX 1 Search Strategies}

\begin{tabular}{|c|c|}
\hline 1 & exp osteoporosis/ and exp data collection/ and exp public health/ and (nation* or population*).ti,ab. \\
\hline 2 & limit 1 to (english language and humans and yr="1990-2009" and "all adult (19 plus years)") \\
\hline \multicolumn{2}{|c|}{ Embase (1990 to 2009 week 23) } \\
\hline 1 & exp osteoporosis/ \\
\hline 2 & exp “population and population related phenomena"/or exp disease surveillance/ \\
\hline 3 & (nation* or population*).ti,ab. \\
\hline 4 & $\begin{array}{l}\text { exp data collection method/ or exp mass screening/ or exp health survey/ or exp mathematical } \\
\text { phenomena/ }\end{array}$ \\
\hline 5 & 1 and 2 and 3 and 4 \\
\hline 6 & limit 5 to (yr=1990-2009 and human) \\
\hline \multicolumn{2}{|c|}{ Global Health (1990 to May 2009) } \\
\hline \multicolumn{2}{|c|}{1 (nation* or population*).ti,ab. } \\
\hline 2 & osteopor*.ti. \\
\hline \multicolumn{2}{|r|}{ (surveillanc* or survey* or screening* or questionnair* or data*).ti,ab. } \\
\hline 4 & 1 and 2 and 3 \\
\hline 5 & limit 4 to $y r=1990-2009$ \\
\hline \multicolumn{2}{|c|}{ CINAHL (1990 to June 2009 week 3) } \\
\hline 1 & TI(nation* or population*) \\
\hline 2 & AB(nation* or population*) \\
\hline 3 & $\mathrm{TI}($ osteopor $)$ \\
\hline 4 & TI(surveillanc* or survey* or screening* or questionnair* or data*) \\
\hline 5 & $\mathrm{AB}$ (surveillanc ${ }^{*}$ or survey* or screening ${ }^{*}$ or questionnair* or data*) \\
\hline \multirow[t]{3}{*}{6} & (S1 or S2) and S3 and (S4 or S5) \\
\hline & Google (1990 to May $\left.14^{\text {th }}, 2009\right)$ \\
\hline & osteoporosis (national OR population) (indicators OR surveillance OR “health indices") \\
\hline
\end{tabular}




\section{References}

1. Public Health Agency of Canada. Public Health Agency of Canada strategic plan, 2007-2012: information, knowledge, action [Internet]. Ottawa (ON): Public Health Agency of Canada; 2007 [cited 2009 Dec 10]. Available from: http://www.phac-aspc.gc.ca /publicat/2007/sp-ps/pdfs/PHAC _StratPlan_E_WEB.pdf

2. Public Health Agency of Canada. Report on plans and priorities 2009-2010 [Internet]. Ottawa (ON): Public Health Agency of Canada; 2009 [cited 2009 Dec 10]. Available from: http://www.tbs-sct.gc.ca/rpp/2009-2010 /inst/ahs/ahs-eng.pdf

3. Shiller SK, Bierman AS. Introduction to the POWER Study. In: Bierman AS, editor. Project for an Ontario Women's Health Evidence-Based Report, Volume 1. Toronto (ON): Echo; 2009. Jointly published by St. Michael's Hospital and ICES.

4. Canadian Institute for Health Information, Health Indicators 2010 [Internet]. Ottawa (ON): Canadian Institute for Health Information; 2010 [cited 2010 Nov 5]. Available from http://secure.cihi.ca/cihiweb /products/Healthindicators2010_en.pdf

5. Health Canada. Healthy Canadians-a federal report on comparable health indicators 2008 [Internet]. Ottawa (ON): Health Canada; 2009 [cited 2009 Dec 10]. Available from: http://www.hc-sc.gc.ca/hcs-sss/pubs /system-regime/index-eng.php

6. Canadian Institute for Health Information. Pan-Canadian primary health care indicators, Report 1, Volume 1: Pan-Canadian Primary Health Care Indicator Development Project [Internet]. Ottawa (ON): Canadian Institute for Health Information; 2006 [cited 2010 Nov 5]. Available from: http://secure.cihi.ca / cihiweb/products/PHC_Indicator _Report_1_Volume_1_Final_E.pdf

7. Canadian Institute for Health Information. Pan-Canadian primary health care indicators, Report 1, Volume 2: Pan-Canadian Primary Health Care Indicator Development Project [Internet]. Ottawa (ON): Canadian Institute for Health Information; 2006 [cited 2010 Nov 5]. Available from: http://secure.cihi.ca / cihiweb/products/PHC_Indicator _Report_1-Volume_2_Final_E.pdf
8. Canadian Institute for Health Information. Enhancing the primary health care collection infrastructure in Canada, Report 2: Pan-Canadian Primary Health Care Indicator Development Project [Internet]. Ottawa (ON): Canadian Institute of Health Information; 2006 [cited 2010 Nov 5]. Available from: http://secure.cihi.ca/cihiweb /products/PHC_Indicator_Report_2 _Final_E.pdf

9 Pan-Canadian Public Health Network. Indicators of health inequalities: a report from the Population Health Promotion Expert Group and the Healthy Living Issue Group for the Pan-Canadian Public Health Network [Internet]. Ottawa (ON): Pan-Canadian Public Health Network; 2009 [cited 2010 Nov 5]. Available from: http://www.phn-rsp.ca/pubs/ihi-idps /pdf/Indicators-of-Health-InequalitiesReport-PHPEG-Feb-2010-EN.pdf

10. Stewart, P. Chronic Disease Indicator Framework, Centre for Chronic Disease Prevention and Control, Public Health Agency of Canada; 2007 (unpublished).

11. Public Health Agency of Canada. What is the impact of osteoporosis in Canada and what are Canadians doing to maintain healthy bones: fast facts from the 2009 Canadian Community Health SurveyOsteoporosis Rapid Response [Internet]. Ottawa (ON): Public Health Agency of Canada; 2010 [cited 2011 Aug 26]. Available from: http://www.phac-aspc.gc.ca/cd-mc /osteoporosis-osteoporose/index-eng.php

12. Melton LJ 3rd. Epidemiology worldwide. Endocrinol Metab Clin North Am. 2003;32(1):1-13.

13. Papaioannou A, Morin S, Cheung AM, Atkinson S, Brown JP, Feldman S, et al; Scientific Advisory Council of Osteoporosis Canada. 2010 clinical practice guidelines for the diagnosis and management of osteoporosis in Canada: summary. CMAJ. 2010;182(17):1864-73.

14. Boulkedid R, Abdoul H, Loustau M, Sibony O, Alberti C. Using and reporting the Delphi method for selecting healthcare quality indicators: a systematic review. PLoS One. 2011;6(6):e20476. doi: 10.1371 /journal.pone.0020476
15. Ganann R, Ciliska D, Thomas H. Expediting systematic reviews: methods and implications of rapid reviews. Implementation Sci. 2010;5:56. doi: 10.1186/1748-5908-5-56

16. Fink A, Kosecoff J, Chassin M, Brook RH. Consensus methods: characteristics and guidelines for use. Am J Public Health. 1984;74(9):979-83.

17. Majumdar SR, Johnson JA, Bowker SL, Booth GL, Dolovich L, Ghali W, et al. A Canadian consensus for the standardized evaluation of quality improvement interventions in Type 2 Diabetes. Can J Diabetes. 2005;29(3):220-9.

18. Clark JP, Bierman AS. The POWER Study Framework. In: Bierman AS, editor. Project for an Ontario Women's Health Evidence-Based Report: Volume 1. Toronto (ON): Echo; 2009. Jointly published by St. Michael's Hospital and ICES.

19. Australian Institute of Health and Welfare. National indicators for monitoring osteoarthritis, rheumatoid arthritis and osteoporosis [Internet]. Canberra: Australian Institute of Health and Welfare; 2006 [cited 2010 Oct 26]. Available from: http:// www.aihw.gov.au/publications/phe /nimorao/nimorao.pdf

20. European Community Health Indicators Working Group. Design for a set of European Community health indicators: final report by the ECHI Project. Bilthoven (NL): National Institute of Public Health and the Environment; 2001. 